\title{
The Origins of British Paediatric Hospitals
}

The establishment of special hospitals for children began in France early in the nineteenth century. In 1802 the Maison Nationale des Orphelines, founded in 1751 as the Maison Royale de l'Enfant-Jésus, an orphanage for girls, was converted into an hospital for children between the ages of two and fourteen years. ${ }^{1}$ The new institution, called the Enfants Malades (usually spelled Enfans until about 1830), was large since it was intended for the reception of all Parisian children requiring hospital care. Henceforth, all other hospitals, apart from those for cutaneous and venereal diseases, were prohibited from admitting children. By 1815 the Enfants Malades was caring for six to eight hundred inpatients at any one time. ${ }^{2}$ Also the seventeenth-century foundling hospital, the Enfants Trouvés, was reorganized in 1795 when the national convention appropriated ecclesiastical property at Port-Royal to form a maternity and infant hospital. Although the institution was still intended mainly for the reception of abandoned babies, so many of these died-the mortality during the six months from September, 1800 until March, 1801 was 93 per cent-that the Enfants Trouvés of necessity became a hospital for sick babies. ${ }^{3}$ Beginning in the 1830s other countries began to copy the French example. By mid-century children's hospitals had been created in St. Petersburg (1834), Vienna (1837), Pest (1839), Moscow (1842), Prague (1842), Turin (1843), Berlin (1843 and 1844), Graz (1844), Copenhagen (1845), Turin (1845), Munich (1846) and Constantinople (1847). The British, however, did not follow suit until 1852 when the London Hospital for Sick Children (Great Ormond Street) was opened with some trepidation. ${ }^{4}$ This 'pilot project' was perceived as a success for, by 1869 , London had five paediatric hospitals, and by 1890 the number in the metropolis had risen to eleven.

Large cities, such as Manchester and Liverpool, followed the London example, and also smaller cities, such as Sunderland and Norwich. By the end of the century, more than twenty-five paediatric hospitals had been established in Great Britain, plus many more institutions that offered specialized services for children rather than general medical care. Of all the special hospitals, the paediatric ones became the most favoured, perceived by most citizens as charitable institutions fulfilling the humanitarian requisite of providing helpless children with medical and nursing care unavailable in their own homes. This enthusiasm was not usually shared by local general practitioners who considered

1 G.-R. Siguret, Histoire de l'hospitalisation des enfants malades de Paris (Paris: A. Michalon, 1907), p. 50.

2 John Cross, Sketches of the Medical Schools of Paris (London: J. Callow, 1815), p. 171.

${ }^{3}$ Albert Dupoux, Sur les pas de Monsieur Vincent: Trois cents ans d'histoire parisienne de l'enfance abandonnée (Paris: Revue de l'Assistance Publique, 1958), p. 179.

${ }^{4}$ Histories of the London Hospital for Sick Children are: Thomas Twistington Higgins, 'Great Ormond Street' 1852-1952 (London: Odhams Press, 1952); Jules Kosky, Mutual Friends: Charles Dickens and Great Ormond Street Children's Hospital (London: Weidenfeld and Nicolson, 1989); Jules Kosky and Raymond J. Lunnon, Great Ormond Street and the Story of Medicine (London: Hospitals for Sick Children and Granta, 1991); and R. A. Clavering, 'Dr. Charles West and the Founding of the Children's Hospital in Great Ormond Street' (1956, MS in the Great Ormond Street Archives, hereafter G.O.S. Archives). 
themselves robbed of patients by the free services offered through the hospital outpatient departments. Also, the steadily increasing admission of babies as inpatients caused concern to a few paediatricians, such as Abraham Jacobi in the United States who, in 1870, was dismissed from the medical board of the Nursery and Child's Hospital in New York City for publicizing the high mortality rate of babies reared in the institution. ${ }^{5}$ As will be seen, and as was also pointed by Charles West, the founder of Great Ormond Street, babies did not thrive in acute hospitals let alone in long-stay asylums. But the trend, both lay and medical, was in favour of institutions and few people objected to increasing the number of hospital beds for children until recently, when the findings of Rene Spitz, John Bowlby, and other psychiatrists raised concern as to the long-term mental effects of separating children, particularly infants, from parents and families. ${ }^{6}$

Ironically enough, in the early nineteenth century the moral danger of removing children from their families had been advanced as a main reason for not establishing paediatric hospitals. However, the driving motives were the Malthusian fear that assistance to poor families would lead to a socially undesirable increase in birth rate reinforcing the more traditional concept that neither the state, nor any other institution, should relieve parents of their responsibilities to their offspring, rather than any great concern about the welfare of children. ${ }^{7}$ A writer in the Edinburgh Review of 1823 expressed prevailing sentiments thus:

To relieve the parents wholly from the burthen of maintaining their offspring, would be absurd, even if it were possible; and every scheme which has for its object the gratuitous maintenance of poor children, may safely be pronounced dangerous to society, in proportion as it directly relieves the parent from his burthen. It removes the only check upon improvident marriages, and one of the principal guards of chastity. An hospital for the support of children is liable to this objection in the highest degree, and a foundling hospital more than any other. ${ }^{8}$

Malthusian and laissez faire doctrines of the early nineteenth century added fuel to morally based, previous constraints on providing institutional care for sick and abandoned children. The census of 1801 set the population of England and Wales at about nine million, a larger figure than anticipated, and consequently a disincentive to charitable action for the preservation of life. As we have seen, George Armstrong's eighteenth-

\footnotetext{
5 For Abraham Jacobi's extensive analysis of mortality in foundling institutions see his papers, 'Foundlings and Foundling Institutions', in William J. Robinson (ed.), Collectanea Jacobi (New York: The Critic and Guide Company, 1909), vol. 1, pp. 217-318, and 'In Re the Nursery and Child's Hospital', ibid., vol. 8, pp. 11-48; both papers are reprinted in Janet Golden (ed.), Infant Ayslums and Children's Hospitals: Medical Dilemmas and Developments 1850-1920, An Anthology of Sources (New York: Garland, 1989). For an account of Jacobi's dissension with the managers of Nursery and Child's Hospital, New York, see: Virginia A. Metaxas Quiroga, 'Female Lay Managers and Scientific Pediatrics at Nursery and Child's Hospital, 1854-1910', Bulletin of the History of Medicine, 60 (1986): 194-208.

6 Rene A. Spitz, 'Hospitalism: An Inquiry into the Genesis of Psychiatric Conditions in Early Childhood', Psychoanalytic Study of the Child, 1 (1945): 53-74, and 'Hospitalism: A Follow-up Report on Investigation Described in Volume I, 1945', ibid., 2 (1946): 113-17; John Bowlby, Maternal Care and Mental Health: A Report Prepared on Behalf of the World Health Organization as a Contribution to the United Nations Programme for the Welfare of Homeless Children (Geneva: W.H.O., 1951).

7 The sanctity of the family is discussed in Ivy Pinchbeck and Margaret Hewitt, Children in English Society, Volume II (London: Routledge \& Kegan Paul, 1973), pp. 357-61.

8 'Early Moral Education', Edinburgh Review, 38 (1823): 437-53.
} 


\section{The Origins of British Paediatric Hospitals}

century dispensary for children in London failed for lack of sustained financial support. Eduard Seidler has pointed out that this dispensary was the earliest institution in Europe exclusively dedicated to the medical care of children, which suggests that British physicians, or more properly Scottish ones, were not wanting in initiative. ${ }^{9}$ The difficulty was in obtaining patronage for a charity perceived in principle as unnecessary or even positively harmful to the interests of the governing classes, since it would interfere with the natural checks to the expansion of the lower orders. John Bunnell Davis, who succeeded in founding the Universal Dispensary for Children in 1816, marshalled powerful arguments to counteract prevailing indifference to the fate of needy children. In opposition to the theory that letting the poor shift for themselves favoured the national economy, he pointed out that 'by relieving the sufferings of the helpless infant poor, by studying the most advantageous means to preserve and strengthen their constitutions', one could 'impart to them that vigour in their early days, that will ensure a healthy population, and enable the poor to support those labours from which the rich extract their competence and resources'. ${ }^{10}$ In addition to providing treatment for sick children, his dispensary would serve to teach parents about infant management and nursing care, while also providing facilities for physicians to learn about the diseases of children. Later in the century these would remain the standard arguments for establishing paediatric hospitals.

In the meantime the dispensary movement spread for a few years then ground to a halt. In 1820 the Royal Western Infirmary for Children was opened, with two stations in Marylebone and one in Westminster. By 1823, Davis's dispensary had received royal patronage and moved to Waterloo Road. In 1829 a General Dispensary for Children was established in Manchester. Then nothing further in Lancashire, or elsewhere, until 1851 when Liverpool opened an Institution for the Diseases of Children. (Both these provincial dispensaries were direct forerunners of paediatric inpatient hospitals to be established in the late 1850s. ${ }^{11}$ ) The dearth of any new paediatric dispensaries during the 1830 s and 1840s supports John Pickstone's contention that during this period 'charity had become unpopular with reformers who increasingly placed their faith in "political economy". ${ }^{12}$ The 1834 Poor Law Amendment Act epitomized this line of thought by restricting public aid to absolutely helpless people and leaving the rest to fend for themselves and their families. The able-bodied would be obliged to work and so, it was believed, enrich an economy which had infinite capacity for expansion so long as it was not restrained nor short of labour. Not only public but also private charity were perceived as constraints to the realization of this ideal. A reaction to the harshness of liberal laissez faire occurred in the $1850 \mathrm{~s}$ when it became possible for medical men to find patrons not merely for dispensaries but also for paediatric institutions offering inpatient care. Before looking into the reasons for this altered climate of charity it is worth surveying the medical care available for children before mid-century.

\footnotetext{
9 Eduard Seidler, 'An Historical Survey of Children's Hospitals', in Lindsay Granshaw and Roy Porter (eds.), The Hospital in History (London: Routledge, 1989), pp. 181-97.

10 John Bunnell Davis, A Cursory Inquiry into the Principal Causes of Mortality in Children (London, 1817), p. 33.

11 Alfred White Franklin, 'Children's Hospitals', in F. N. L. Poynter (ed.), Evolution of Hospitals in Britain (London: Pitman, 1964), pp. 103-21.

12 John V. Pickstone, Medicine and Industrial Society: A History of Hospital Development in Manchester and its Region, 1752-1946 (Manchester: University Press, 1985), p. 54.
} 


\section{Elizabeth M. R. Lomax}

Four or five special dispensaries scattered round the country could make only a minute contribution to child health care. Otherwise, children took their chances as outpatients at the regular dispensaries and were occasionally admitted to general hospitals, usually for surgical emergencies such as burns, scalds and broken bones. As indicated by Loudon, begining in 1770 John Coakley Lettsom had led a movement to establish general dispensaries which, like the voluntary hospitals, were financed by subscriptions. ${ }^{13}$ The movement proved popular for, by 1800 , London possessed sixteen dispensaries, a further twenty-two had been established in the provinces, and together all these institutions admitted at least 100,000 patients each year. Marjorie Cruickshank has described the facilities available in the industrial North West. ${ }^{14}$ She indicates that children of all ages, bearing the essential subscribers' recommendations, were to be found in queues outside the general dispensaries. (Later in the century many of these would become general hospitals or infirmaries admitting inpatients). In theory some of these institutions did not admit children, but in practice such regulations were not usually rigorously maintained. Manchester had its own special Dispensary for Children which, by the 1840 s, was treating 2,000 patients annually. ${ }^{15}$ Here too subscribers' letters were required but, once this hurdle was surmounted, provisions were generous in that there were no restrictions on place of residence, medicaments were free, and patients were visited in their own homes if thought necessary. As will be seen, this custom of home visiting by the medical staff was continued when the children's dispensary became a hospital, and persisted at the end of the century when most other paediatric hospitals had given up outside assistance as unnecessary and financially burdensome. Before the mid-century children were also admitted, in unknown but presumably small numbers, as inpatients to the general infirmaries. The largest northern one, the Manchester Royal Infirmary, received children injured by accidents, and some requiring removal of bladder stones or the correction of deformities. ${ }^{16}$ The hospital statistics did not indicate the age of patients but, in 1860, John Roberton provided an analysis of fatal cases at the Manchester Royal Infirmary to reinforce his plea for additional and improved accommodation for surgical patients. ${ }^{17}$ During the previous twelve months, 279 deaths were reported at the hospital of which 202 were among surgical patients, with 50 occurring in children under fourteen years of age. Five children had been 'run over', but most, 37 according to Roberton's figures, had died as a consequence of burns and scalds (see Table 10, Appendix). Nor was this an unusual situation for no less than 142 children under the age of ten years had died from burns at the Manchester Royal Infirmary in the previous five years.

In 1843 a committee looking into the need for special paediatric institutions found only 136 children under the age of ten years in the London general hospitals. ${ }^{18}$ If the committee had also investigated Poor Law institutions it would have found therein far larger numbers

\footnotetext{
13 I. S. L. Loudon, 'The Origins and Growth of the Dispensary Movement in England', Bulletin of the History of Medicine, 55 (1981): 322-42.

${ }_{14}$ Marjorie Cruickshank, Children and Industry: Child Health and Welfare in North-West Textile Towns during the Nineteenth Century (Manchester: University Press, 1981).

15 Ibid., p. 77.

16 Ibid., p. 76.

17 John Roberton, 'On the Need of Additional as well as Improved Hospital Accommodation for Surgical Patients in Manufacturing and Mining Districts but especially in Manchester', paper read to the Manchester Statistical Society (12th November, 1860).

18 'Proposed Hospital for Sick Children', Lancet, i (1851): 331.
} 
of children in varying states of ill health, but workhouses and their inmates formed a subset apart from general consideration. In so far as the London general hospitals were concerned, statistics from the Registrar-General's office showed that 13 infants and 189 children between the ages of one and ten years died in the twelve major hospitals in $1840 .{ }^{19}$ Examination of the reported causes of death indicates that extremely sick children were admitted, since 6 of the infants had died of smallpox, a very lethal disease in the first months of life, and two had succumbed to 'violent deaths' (see Table 16). Among the older children, no less than 143 were classified as dying 'violent deaths', which suggests that they were admitted in extremis following severe accidental or deliberate injury. Since the number of children admitted to these hospitals during the year is unknown, one cannot estimate the percentage that died. However, the above gloomy picture indicates that general hospitals were not always trying to produce favourable statistics by excluding dangerously ill patients since the children they admitted were often suffering from smallpox or scarlet fever, or were accident cases many of whom would die of immediate shock or of sepsis within a few days. ${ }^{20}$

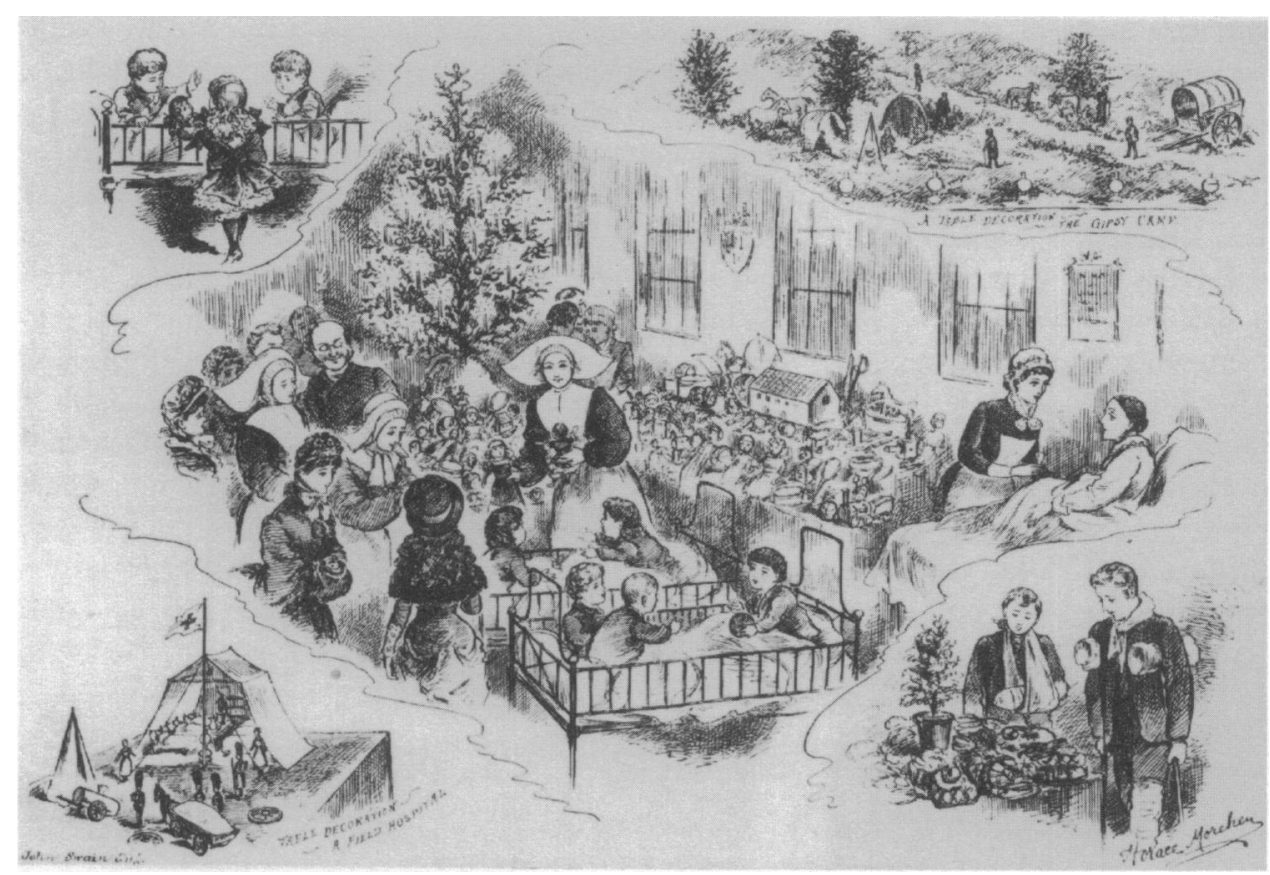

Figure 2: Christmas at University College Hospital, 1884, photo-engraving by Joseph Blomely (John) Swain, after a drawing by Horace Morehen. (The Welcome Institute Library, London.)

19 Appendix to Fourth Annual Report of the Registrar-General (London, 1842), pp. 198-9. The twelve hospitals were: St. George's, Charing Cross, Middlesex, London Fever, the Small Pox, University College, Westminster, St. Bartholomew's, London, Guy's, St. Thomas's, and King's College.

${ }^{20}$ For an analysis of the contribution of provincial hospitals to the treatment of major illness and causes of mortality, see: S. Cherry, 'The Hospitals and Population Growth: The Voluntary General Hospitals, Mortality and Local Populations in the English Provinces in the Eighteenth and Nineteenth Centuries', Population Studies, 34 (1980): 59-75 and 251-65. 


\section{Elizabeth M. R. Lomax}

When children were admitted it was usually to adult wards. Girls and younger boys were placed with women patients who were expected to help in their care. Older boys were admitted to men's wards. Not until the twentieth century would children's wards become commonplace, although Guy's Hospital, under the instigation of Dr. Golding Bird, opened a Children's Department with paediatric beds in $1848 .^{21}$ However these wards were demolished four years later to make way for new buildings. The paediatric department concept was abandoned for the next sixty years for the reason, so commonly given in the nineteenth century, that a special ward for children required too many nurses to be economically justifiable. ${ }^{22}$ More permanent arrangements prevailed at the London Hospital where a children's ward was established probably as early as $1840 .^{23}$ In 1857 , 214 patients under seven years of age, mostly suffering from burns, fractures and wounds or contusions, were admitted to this then eighteen bedded ward. ${ }^{24}$ In 1867 an extra floor was added to University College Hospital which resulted in the dedication of two wards for the use of children. ${ }^{25}$ On the other hand, at St. Bartholomew's children were still being mixed with adult patients as late as $1923 .^{26}$ By this time most of the other teaching hospitals had either developed special paediatric wards (in part because of fears, which surfaced early in the twentieth century, of children catching tuberculosis from adult patients) or were affiliated with children's hospitals for the instruction of medical students.

In the main, general hospitals admitted children seriously ill with fever and surgical cases, that is children requiring treatment for accidents, for abscesses, frequently of tuberculous origin but labelled as scrofular at that time, for removal of bladder stones, or with disabilities, such as hare-lip, that could be relieved by surgery. For this reason when special hospitals for children were initiated, some, such as the Hospital for Sick Children at Edinburgh, made provisions to admit only medical cases leaving surgical ones to continue attending the general hospital, in this instance the Edinburgh Royal Infirmary. There, during the three last months of 1853 for example, 10 children had been admitted under the care of James Syme, professor of surgery. ${ }^{27}$ Not until 1887 was a surgical ward opened at the Edinburgh children's hospital. Most other institutions, including Great Ormond Street, initially admitted surgical cases cautiously, and to a far lesser extent than medical ones, in part because they could be cared for elsewhere but also because of the fearful incidence of post-operative infection that prevailed until antiseptic measures were introduced in the seventies. Then, as the operative mortality decreased, paediatric

${ }^{21}$ H. C. Cameron, Mr. Guy's Hospital 1726-1948 (London: Longmans, Green, 1954), pp. 357-8.

22 Ibid.

23 A. E. Clark-Kennedy, The London: A Study in the Voluntary Hospital System (London: Pitman Medical Publishing, 1962), vol. 1, pp. 253-4.

24 'London Hospital: Return of Patients under Seven Years of Age in the Children's Ward during the Year 1857', Lancet, i (1858): 190-1.

${ }_{25}$ W. R. Merrington, University College Hospital and its Medical School: a History (London: Heinemann, 1976), p. 52.

26 Sir D'Arcy Power, A Short History of St. Bartholomew's Hospital 1123-1923 (London, 1923), pp. 112-13.

27 Edinburgh Medical Archives, LHB 1/128/9, Surgical Clinical Ward Journal, Professor Syme, September 13 to December 17,1853 . Nine of the ten patients were boys of whom two were admitted with fractures, one with necrosis of the head of the humerus, one with "disease of the knee", one with a venous aneurysm in the forearm, one with a possible dislocation of the hip joint, one with a wound of the leg, one with "wry neck" for tenotomy, and one with stricture of the urethra. The solitary girl was a baby of eleven months with an erectile tumour of the lip. 


\title{
The Origins of British Paediatric Hospitals
}

hospitals were encouraged to expand their departments of surgery, which were usually as large as the medical ones by the end of the century.

During the 1840 s occasional articles or reviews promoting the establishment of children's hospitals began appearing in medical journals. Two points were commonly made, that the country lacked facilities for the care of sick children, and that as a consequence British physicians with paediatric interests were professionally disadvantaged in comparison to their continental colleagues, particularly to those in Paris. There the state maintained the Hôpital des Enfants Malades which, with at least 600 beds for children between the ages of two and fifteen years, provided exceptional conditions for the clinical and pathological investigation of disease. Specialized papers and monographs flowed from the French medical presses which the British could review but not emulate. In 1841, Baudeloque, Jadelot, Guersant and other French paediatricians launched a new periodical entirely devoted to children's hospitals and illnesses, La Clinique des Hôpitaux des Enfans. In reviewing the new journal (which was perhaps prematurely incubated since it would survive for only four years) the Medico-Chirurgical Review admitted that 'our continental neighbours have the advantage of us, in the numerous facilities they enjoy for studying the diseases of children. . . . Such establishments [as the Enfants Malades] are absolutely and essentially necessary for attaining a knowledge of infantile pathology' ${ }^{28}$ In 1849 the British and Foreign Medico-Chirurgical Review complained that London was 'nearly alone in the want of an hospital for sick children' among the capital cities of Europe, even lacking special provisions for the regular admission of young patients to general hospitals. Consequently physicians received no special training in the diseases of children even though such patients would form about one third of their practice. Eloquently the authors pleaded:

\begin{abstract}
We need an Hôpital des Enfans [sic] Malades in the metropolis, near the schools of medicine; we need men of admitted ability, professional, scientific, and literary, able to stand side by side with the officers of hospitals for adults, prosecuting the study of a special pathology and treatment in its wards, and hence able and willing to impart the results of their experience to the rising generation. ${ }^{29}$
\end{abstract}

However, not all British physicians found the French system attractive enough to emulate. In 1843 the British and Foreign Medical Review indicted the Hôpital des Enfants Malades, and the French foundling hospitals, for their unacceptably high mortality rates, for the prevalence on their wards of diseases, such as thrush, erysipelas, and sclerema, which were commonly fatal, and for the shortage of trained nurses available. ${ }^{30}$ The reviewers doubted the possibility, 'without an enormous expenditure of money', of providing young, sick children with as good a chance of recovery in hospital wards as in their own homes. Given the usually depressing mortality statistics published by continental hospitals, it was difficult to argue that paediatric institutions helped to save children's lives whatever their merits in furthering medical knowledge.

Yet, by mid-century, it was also becoming clear that urban children, particularly those living in manufacturing towns and large seaports, had a much higher death rate than rural

${ }^{28}$ Medico-Chirurgical Review, Ser. 2, 37 (1842): 86-110.

29 'On the Diseases of Children', British and Foreign Medico-Chirurgical Review, 3 (1849): 406-32.

${ }^{30}$ British and Foreign Medical Review, 15 (1843): 322. 
children. The greater mortality seemed to be mainly due to increased prevalence of epidemic disease, chiefly typhus, measles and scarlet fever, and came to be associated with overcrowding and lack of sanitation in working-class dwellings, thus undermining any assumption that home was the best place for recovery. By the 1850s, the government had published a great number of disturbing statistical reports on the national health, beginning in 1837 with annual reports on vital statistics for England and Wales. ${ }^{31}$ Where previously only large towns had collected information on births and deaths, now statistics on all parts of the country were made available allowing for comparison and for the realization that death rates could vary considerably from district to district. The 'abstract of ages' reported the number of deaths for each of various age groups, including six subgroups for infants, the total for those aged under one year, and assessments for each year under the age of five. However, as indicated by William Farr in the second annual report, the figures needed to be cautiously interpreted; they not could be used comparatively unless the proportion of living children to living adults in the different districts was the same. ${ }^{32}$ Furthermore, since birth registration was not compulsory there was no knowing how many infants died without leaving any statistical trace of their brief existence. John Eyler has discussed the many problems, such as age distribution, movement of population and under registration of births and early deaths, that required evaluation before reasonably reliable comparative statistics could be produced. ${ }^{33}$

Nevertheless, even the crude death rates reported in the early annual reports were useful to reformers since they seemed to demonstrate that child mortality rates were far more variable than those of adults and also that infant mortality (under one year of age) everywhere represented a large part of the total mortality, 'sometimes exceeding even a fourth', as indicated by a medical reviewer of the third annual report. ${ }^{34}$ The variability of child mortality, from year to year and from district to district, suggested that it was susceptible to improvement if only the causes of excess deaths among the young could be established and circumvented.

Then, in 1842, Edwin's Chadwick's Report on the Sanitary Condition of the Labouring Population of Great Britain offered impressive numerical evidence of the high mortality of small children living in manufacturing towns. In one table Chadwick listed various urban and rural areas to compare the proportion of deaths occurring before the age of five years in the three, then conventional, social groups. ${ }^{35}$ As might have been predicted, in all geographical areas children belonging to the top social group, composed of the gentry and professionals, were far more likely to survive to the age of five years than the offspring of the lowest social class, which included artisans, servants and labourers. But within this third group, children born in rural counties apparently ran a one in three chance of dying

\footnotetext{
31 A comprehensive discussion of the 'roots of the sanitary idea', including overcrowding and the deterioration of public health conditions, may be found in M. W. Flinn, 'Introduction', in M. W. Flinn (ed.), Report on the Sanitary Condition of the Labouring Population of Gt. Britain, by Edwin Chadwick, 1842 (Edinburgh: University Press, 1965), pp. 1-73.

${ }^{32}$ Noel A. Humphreys, Vital Statistics: A Memorial Volume of Selections from the Reports and Writings of William Farr . . (London: Offices of the Sanitary Institute, 1885), p. 188.

${ }_{33}$ John M. Eyler, Victorian Social Medicine: The Ideas and Methods of William Farr (Baltimore: Johns Hopkins University Press, 1979), pp. 66-96.

34 'Review-Third Annual Report of the Registrar General ...', Medico-Chirurgical Review, Ser. 2, 36 (1842): 305-21.

${ }^{35}$ Chadwick, Report on the Sanitary Condition, pp. 228-9.
} 


\section{The Origins of British Paediatric Hospitals}

before reaching the age of five years, whereas for those born in Manchester or Leeds the risk rose to one in two, and in Liverpool it was as high as two out of three. Chadwick reiterated such comparative statistics throughout the report, to press home his point that sanitary reform was imperative to improve the life expectancy, and morals, of poor city dwellers. Although readers of the report may not have been convinced that better drains were the obvious solution to ill health and immorality, they were probably startled by the statistics demonstrating the poor life expectancy of working-class children. ${ }^{36}$

The reasons why many working-class homes were inimical to health were set out in the 1840 and 1845 reports on the health of towns. The 1840 committee of inquiry was told that one-fifth of the working-class population of Liverpool, more than 39,000 persons, lived in cellars, mostly 'dark, damp, confined, ill-ventilated, and dirty' ${ }^{37}$ In Manchester almost 12 per cent of the working population, nearly 15,000 persons, also dwelt in cellars. ${ }^{38}$ Almost equally injurious to health, according to members of the committee who believed that thorough ventilation of dwellings was essential to prevent miasma and fevers, were the rows of back to back houses especially to be found in Liverpool. A narrow court, containing outdoor privies and closed at each end, separated each row of back to back houses from another identical one. According to the report, 'It is scarcely possible to conceive any construction more prejudicial to the health of the inhabitants' ${ }^{39}$ The sanitary state of working-class districts in Glasgow was reported as the worst in Great Britain, and many districts in East London were described as inconceivably filthy. Given the prevailing belief that miasma, or polluted air, usually generated by the decomposition of human waste matter or dead organic material, was the cause of epidemic disease, then the damp, dirty, evil smelling, and overcrowded dwellings described in the various sanitary reports could only be considered as ideal places for the propagation of disease. No longer could any thoughtful person who read the reports, or their reviews in newspapers and magazines, casually claim that poor children stood a good chance of recovering from serious illness in homes nationally proclaimed so insalubrious.

None the less, collecting sick children together and placing them in a hospital was not necessarily seen as an improvement, the chief objection being the practical one of high likelihood of cross-infection among young patients far more prone to epidemic diseases than adults. For hospitals in general, and those for children in particular, had long been recognized as places where fevers could run riot. The Hospice des Enfants Trouvés and the Hôpital des Enfants Malades were both renowned for the high incidence of infectious diseases on their large wards. In 1835 a medical commission reported that during the six month period, from October 1833 until April 1834, 155 cases of eruptive fever had been nursed on the wards of the Enfants Malades. ${ }^{40}$ Eighty-eight of these children had

36 The interaction of social class with environment in producing high infant mortality rates is discussed in: Naomi Williams, 'Death in its Season: Class, Environment and the Mortality of Infants in Nineteenth-Century Sheffield', Social History of Medicine, 5 (1992): 71-94. Most historians have examined inequalities in infant mortality rates for a later period, for example: R. I. Woods, P. A. Watterson and J. H. Woodward, 'The Causes of Rapid Infant Mortality Decline in England and Wales, 1861-1921', Population Studies, 42 (1988): 343-66, and ibid., 43 (1989): 113-32; and C. H. Lee, 'Regional Inequalities in Infant Mortality in Britain, 1861-1971: Patterns and Hypotheses,' Population Studies, 45 (1991): 55-65.

${ }_{38}$ Report of the Select Committee on the Health of Towns, B.P.P., 1842, XI, p. viii.

38 Ibid., p. $x$.

39 Ibid., para. 2391, evidence of Dr. William Henry Duncan.

40 Siguret, Histoire de l'hospitalisation des enfants, p. 60. 
contracted fever while in the hospital with fatal consequences for 52 of them. These figures were particularly appalling since many of these little patients had originally been hospitalized for only mild illness. The 77 children admitted with fever proved more resilient for only 21 of them died. The more optimistic British reformers believed that such disasters could be attenuated, or even avoided, by ensuring better sanitation, that is greater cleanliness, good ventilation, and adequate spacing between beds, in any hospital being considered. Another proposed policy was to deny admittance to children suffering from fevers and exanthems. Some commentators advocated a special ward, or isolation rooms, for infectious cases while others thought this would cause dangerous concentration of toxic particles in one area and therefore favoured scattering such patients throughout the hospital, so as to dilute the effect of miasma being produced. Isolation actually became standard policy once the specificity of infectious fevers was accepted doctrine, but this was by no means obvious in the 1840 s. Incidentally, not until the late 1870 s did the Enfants Malades acquire special and adequate isolation facilities for children admitted with eruptive fevers, or becoming infected while on the general wards. ${ }^{41}$

While discussions as to the feasibility of hospitals for children continued in the medical press, a young physician, Charles West, was doing his utmost to turn abstractions into reality. Born in 1816 and the son of a Baptist minister who was also a teacher, West received his early education at his father's school. ${ }^{42}$ At the age of fifteen he was apprenticed to a general practitioner, and two years later, in 1833, was accepted as a medical student at St. Bartholomew's Hospital. There he proved himself a bright and diligent student, winning the prize for medicine in 1834, and the following year the prize in forensic medicine and in midwifery. Unable to proceed to Oxford or Cambridge because of his father's religion and occupation, West decided to complete his medical education on the continent. He remained in Bonn for one year, at the end of which he was awarded the university prize for an essay, in Latin, on the female pelvis and its influence on parturition. He then studied in Paris for six months during which time he became acquainted with medical care and teaching at the Hôpital des Enfants Malades and the Hospice des Enfants Trouvés. Finally, West went to the university of Berlin where he was awarded his doctorate in 1837 for a thesis on the female pelvis.

The same year, West returned to London and bought into a city practice, which proved unprofitable for lack of patients. With time on his hands, he spent the summer of 1838 studying obstetrics at the Rotunda Hospital in Dublin, and in 1839 worked for a time as clinical clerk to Dr. George Burrows at St. Bartholomew's. He also attended the outpatient Infirmary for Children in Waterloo Bridge Road and became physician to this institution in 1842. He was appointed lecturer in midwifery, and the diseases of women and children, first at the Middlesex, then at St. Bartholomew's. In 1848 his Lectures on the Diseases of

\footnotetext{
41 A description of the isolation facilities provided in the last decades of the nineteenth century may be found in Paul Weindling, 'From Isolation to Therapy: Children's Hospitals and Diphtheria in fin de siècle Paris, London and Berlin', in Roger Cooter (ed.), In the Name of the Child: Health and Welfare, 1880-1940 (London: Routledge, 1992), pp. 124-45.

42 Biographies of Charles West may be found in the D.N.B.; British Medical Journal, i (1898): 921-3; Lancet, i (1898): 968-70; Felix S. Besser, 'Dr. Charles West, Founder of the Hospital for Sick Childen, Great Ormond Street', Great Ormond Street Gazette (1973): 4-6; Clavering, 'Dr. Charles West and the Founding of the Children's Hospital in Great Ormond Street'; Kosky, Mutual Friends, pp. 35-55 and passim; Kosky and Lunnon, Great Ormond Street, pp. 5-6 and passim; Higgins, 'Great Ormond Street' 1852-1952, passim.
} 


\section{The Origins of British Paediatric Hospitals}

Infancy and Childhood were published, followed by Lectures on the Diseases of Women in 1858. Both texts were well received, the one on diseases of children being assessed by a medical reviewer as 'standing by itself upon its important subject, in our languageunapproached-unrivalled' ${ }^{43}$ In spite of his energy and capabilities, West failed to obtain the professional recognition he expected. His efforts, from 1843 onwards, to convert the Infirmary in Waterloo Bridge Road from a dispensary to a hospital failed, in part due to 'the jealousy of local medical men', who presumably feared losing private patients to the projected institution. ${ }^{44}$ Furthermore, West felt slighted at St. Bartholomew's where he was appointed honorary physician accoucheur with responsibility for the care of patients but without the prestige of having his own beds. Nor was his name printed in the list of hospital medical officers in the annual reports. After years of waiting in vain to be appointed senior physician, West wrote to the house committee complaining of his anomalous position, but to no avail. According to Norman Moore, the hospital surgeons were unfavorably disposed to him 'perhaps because he had often expressed the opinion that, except Mr. Paget, they were none of them competent to perform the operations required in his ward'. ${ }^{45}$ However true, this was hardly the kind of comment likely to win friends, and in 1861 West resigned from St. Bartholomew's in frustration. Henceforth he would devote himself to paediatrics and to Great Ormond Street, although here too there would be problems and disillusionment, as will be seen.

After the fiasco at Waterloo Road, West realized the need for an influential patron. He was advised to approach a leading London physician, Dr. Henry Bence Jones, who agreed to co-operate in the undertaking and lent his house for the meetings of a provisional committee. 'His social influence', according to West, 'was so much greater than mine that the majority gave their names and their money at his request, and some gave also their active cooperation'. ${ }^{46}$ West would later frequently draw attention to his own inability to sway people of rank and power. 'Dr. Jones had influential friends out of the profession, while I had none', he was to state candidly in 1877 , when fighting to retain contact with his beloved hospital at Great Ormond Street. ${ }^{47}$ Bence Jones' friends helped to form a provisional committee which first met in January 1850 with nine members: Drs. Bence Jones and Charles West, Hon. J. W. Percy, Mr. J. Hoare, Captain Frederick Holland, Rev. W. Niven, Mr. E. Futvoye, Mr. William Henry Baillie and Mr. Henry Allen Bathurst. Bathurst was appointed honorary secretary, and filled this onerous position for the next ten years. The noted philanthropist, Lord Ashley, who became the seventh Earl of Shaftesbury in 1851, was persuaded to become chairman of the committee, then president of the hospital until his death in 1885 . Also, as pointed out by Jules Kosky, who discusses the activities and backgrounds of all the original founders of the hospital, other noblemen, the Marquess of Blandford, Lord Effingham and Lord Gosford, shortly also became members of the provisional committee. ${ }^{48}$

Like the Foundling Hospital in the eighteenth century, Great Ormond Street began with a most distinguished patronage. Although West was to be the workhorse, organizing and

43 'On the Diseases of Children', British and Foreign Medico-Chirurgical Review, 3 (1849): 406-32.

44 'Obituary-Charles West', British Medical Journal, i (1898): 921-3.

45 Norman Moore, The History of St. Bartholomew's Hospital (London, C. A. Pearson, 1918), vol. 2, p. 729.

46 'Obituary-Charles West', British Medical Journal, i (1898): 921-3.

47 Charles West, A Letter to the Governors of the Hospital for Sick Children (London, 1877), p. 5.

48 Kosky, Mutual Friends, pp. 117-42. 
directing the necessary alterations to transform 49, Great Ormond Street into an hospital, furnishing the building, setting up a method of accounting, drawing up rules and establishing dietaries, the survival of the projected institution depended not only on his efficiency, or on that of the incoming medical and nursing staff but also, and perhaps to a larger extent, on the fame and social standing of the founders and governors. The aristocracy and upper class provided an example which encouraged others to donate money to the hospital. Furthermore, although the foundation of Great Ormond Street was primarily due to the inspiration and energy of Charles West, he was never able to dominate hospital medical policy. Always ready to proffer advice and, at least in the early years, the ready initiator of novel projects, he could not issue commands but only persuade fellow members of the medical and management committees to agree. West was not particularly good at persuasion, or compromise, and gradually became embittered when hospital policy veered off in directions of which he did not approve. Early signs of future tension occurred in October 1854, when West handed in his resignation as physician to the hospital. ${ }^{49}$ Two weeks later he changed his mind, withdrawing his resignation to the apparent contentment of the management and medical committees. But the reports do not reveal the causes of this incident nor of its resolution. Twenty years later tensions between West and his colleagues had become insuperable, and he was then allowed to resign without demur.

Following Great Ormond Street, small paediatric hospitals were founded at Norwich (1853), Manchester (1855), and at Liverpool, which dated its inception as 1851, the year a dispensary was opened, but which did not have facilities for inpatients until 1858. Then, during the 1860s, no less than eleven paediatric hospitals were founded in Great Britain, beginning with the Edinburgh Hospital for Children in 1860, followed by one in Birmingham in 1861, and in Bristol in 1866 (an institution that commenced as a dispensary in 1857). At this point London again came to the fore with the Victoria Hospital for Children opening in 1866, the North Eastern Hospital, Hackney, and the Hospital for Hip Diseases in Childhood in 1867, the East London Hospital, Shadwell, in 1868, and the Evelina Hospital in 1869. Also founded in the late 1860 s were paediatric hospitals at Gloucester (1867), Brighton (1868) and Nottingham (1869) (see Table 1).

As M. Jeanne Peterson and Lindsay Granshaw have pointed out, establishing special hospitals was an acceptable form of 'medical enterprise' in the nineteenth century. ${ }^{50}$ Ambitious men who lacked the family background, elite education, and influential friends necessary to obtain senior appointments in the voluntary hospitals could make a name through specialization. The trick was to develop expertise in a speciality not catered for by the general hospitals. Originally fields outside regular medicine, such as midwifery, the care of the insane, and bone setting, had been cultivated by men and women, often with special skills and able to attract patients, but without medical qualifications. By the early nineteenth century these so-called empiricists, or quacks, were being displaced, usually against their will, by qualified medical practitioners. Best known perhaps, and skilfully

49 G.O.S. Archives, Medical Committee Minute Books, 18 October, 1854.

50 Lindsay Granshaw, "“Fame and Fortune by Means of Bricks and Mortar": the Medical Profession and Specialist Hospitals in Britain, 1800-1948', in Granshaw and Porter (eds), The Hospital in History, pp. 199-220; M. Jeanne Peterson, The Medical Profession in Mid-Victorian London (Berkeley: University of California Press, 1978), pp. 259-82. 


\section{The Origins of British Paediatric Hospitals}

described by Jean Donnison, was the emergence of the man-midwife in the eighteenth century leading not to the demise of his traditionally female counterpart, but to her being relegated to subordinate status and loosing her former access to the rich clientele. ${ }^{51}$ The rise of the male midwife, soon to bear the more sophisticated designation of obstetrician, went hand in hand with the establishment of lying-in hospitals during the second half of the eighteenth century. By the middle of the next century, dermatology, venereology, pulmonary disease, ophthalmology and orthopaedics had also become flourishing medical fields represented by one or more special hospitals (five for eye diseases, four for pulmonary illness, and three for orthopaedics). ${ }^{52}$

Not only Great Ormond Street but also many subsequent children's hospitals were founded by medical outsiders, that is men who, although usually well or even extremely well qualified, were excluded from senior positions in the general hospitals because of backgrounds perceived as unsuitable. Foreign birth and medical training, religious affiliation to Roman Catholicism or a dissenting church which usually also involved not being educated in Church of England schools, and lower-middle-class parentage were the kind of attributes that branded a man as potential misfit in the tight social group that governed the traditional hospitals. Since perpetuation of the comfortable status quo was the usual objective of governing bodies, their suspicions were not misplaced, for most of the ambitious 'outsiders' were intransigent men who had come almost within reach of high hospital status through the exercise of will rather than of charm or subtlety.

For a determined man it was easier to attain professional and social standing in the provinces than in London where intense competition allowed for great selectivity. In the provinces backgrounds were less carefully scrutinized and, in general, less hospital nepotism prevailed. After all, cities like Manchester had built their wealth on the entrepreneurial spirit which came in all shapes and guises. The influence of the traditional landed aristocracy, never as strong in Lancashire as in most other English counties, was continuously being diluted by recruits from successful commerce and industry. ${ }^{53}$ In this relatively fluid society even foreigners could make their mark so long as their communities had sufficient wealth and cohesion to provide the would-be entrepreneurs with initial backing. John Pickstone has pointed out that, from 1830 to 1850 , funds for the founding and maintenance of hospitals were hard to find in the Manchester area ${ }^{54}$ Local reformers, he explains, had adopted the philosophy of political economists, such as Nassau Senior and Edwin Chadwick, which deprecated unconditional charity as a discouragement to thrift, providence, and honest labour. The revival of fortunes of voluntary hospitals at mid-century, according to Pickstone, began with the charities directed to the care of women and children. Renewed interest in child health in Manchester was partially mobilized by two immigrant physicians, the Hungarian August Schoepf Merei and the German Louis Borchardt, already specialized in the diseases of children in their own countries. 'Both', in Pickstone's words, 'used this knowledge and

\footnotetext{
51 Jean Donnison, Midwives and Medical Men: A History of Inter-Professional Rivalries and Women's Rights (London: Heinemann, 1977).

52 Peterson, The Medical Profession, pp. 262-3.

53 For an analysis of the relationships between landed society and industrial wealth in Lancashire from 1770 to 1850, see: John K. Walton, Lancashire: A Social History, 1558-1939 (Manchester: University Press, 1987), pp. $125-40$.

54 Pickstone, Medicine and Industrial Society, p. 54.
} 
their connections with immigrant merchants to develop their medical practices in their adopted homeland. Manchester, with its cosmopolitan middle class and its high child death rates, was fertile ground for their work' ${ }^{55}$ In 1829 Manchester had followed the example of London in establishing a children's dispensary, the only other city in England to do so apart from Liverpool which followed suit in 1851. But by mid-century the children's dispensary in Manchester was floundering for lack of money until 1853 when a donation from Mr. Knowles, the owner of the Manchester Theatre Royal, not only restored financial integrity but also prompted efforts to expand the institution. ${ }^{56}$ While Borchardt was persuading the governors of the dispensary to arrange inpatient accommodation, Merei, together with James Whitehead, surgeon to the Manchester Lying-in Hospital, was inducing a group of German businessmen to fund a clinical hospital focused on the investigation, as well as the treatment, of children's diseases. He only obtained a dispensary, the Clinical Hospital for Diseases of Women and Children (later to become the Northern Hospital) but, as will be seen, right from its inception in 1856 it functioned as a locus for paediatric research.

How Merei would have coped with the governing board of his hospital will be never be known, since he died in 1857, but Borchardt seems to have dominated both the medical staff and the board of management at the Manchester General Hospital and Dispensary for Sick Children. The governors were content to give him a free hand in running the institution, presumably so saving themselves a lot of work while retaining the honour of being on the board; the rest of the medical officers might fret and fume but could do little so long as Borchardt retained the full confidence of the management. Two publicized hospital scandals were required before the medical staff gained more equable representation in hospital affairs. Borchardt may have been more autocratic than most hospital founders, or may simply appear so because of the publicity surrounding the quarrels at his institution, but most medical promoters of 'special' hospitals sought the kind of power and influence he achieved. Whether or not they succeeded in so doing depended on a multiplicity of factors but perhaps the most critical was to be in at ground level as sole medical advisor to a board of governors consisting of friends and allies. On this count West lost out from the beginning since he needed the support of more eminent physicians, particularly Dr. Henry Bence Jones, to promote his project. He therefore shared authority with them when the institution became functional and was never the medical superintendent of his hospital as was Borchardt in Manchester. At Great Ormond Street initially Bence Jones was the only physician on the committee of management, while the active hospital doctors, West, William Jenner and the surgeon, Athol Johnson, were members of the medical committee only. In 1855 the three medical officers were admitted to the committee of management and a precedent set for the senior hospital physicians and surgeons to be members of this committee. Great Ormond Street was to prove unusual in so permitting all its chief medical officers to participate in management at this early date. For, as will be seen, the paediatric hospitals later to be opened made no such provision, either totally excluding their medical officers from administration or only including the medical founder, who thus effectively wielded authority over the rest.

\footnotetext{
55 Ibid., p. 118.

56 General Hospital and Dispensary for Sick Children ... Report of the Proceedings and Addresses at a Public Meeting on Behalf of this Charity, ... Monday, June 2, 1856 (Manchester, 1856), p. 9.
} 
Thomas Pretious Heslop, the chief initiator of the Children's Hospital at Birmingham, seems also to have been a determined, uncompromising character with a previously checkered career. According to Rachel Waterhouse, Heslop was appointed resident medical officer and tutor to the Birmingham General Hospital in 1848. ${ }^{57}$ Three years later he was reprimanded by the hospital committee for his part in a public row over the efficiency of one of the honorary surgeons to the hospital. Heslop promptly resigned. The following year he was appointed physician to the Queen's Hospital, Birmingham, and professor of physiology at the closely related Medical School. Again disputes arose and by the end of 1858 Heslop had resigned both positions to become a somewhat more lowly physician to the General Dispensary. From there he began organizing the foundation of a children's hospital which was opened in 1862. The rest of his career was more propitious than West's for Heslop also founded the Skin and Lock Hospital at Birmingham, and ended his life as a highly respected citizen, justice of the peace, governor of King Edward School and a trustee of Sir Josiah Mason's Science College. ${ }^{58}$

The Evelina Hospital was unusual in not owing its foundation to any aspiring physician but to the charitable impulses of an extremely wealthy man-Baron Ferdinand de Rothschild. ${ }^{59}$ The son of the Viennese Anselm de Rothschild, Ferdinand married his English cousin, Evelina, and settled in London. When in 1866, one year after their marriage, the Baroness died in childbirth, Ferdinand determined to perpetuate her memory by erecting a maternity hospital in Southwark. Perhaps, as suggested by Priestley, because Guy's Hospital already provided maternity services for Southwark, the Baron later decided to build a children's hospital instead and enlisted the help of Arthur Farre. Already an eminent obstetrician, physician extraordinary to the Queen and physician to various members of the royal family, Farre had no need of any connection with a special hospital to establish himself. Indeed, although he was the first chairman of the committee of management and wielded considerable authority at the Evelina, no mention of his contributions to this hospital are to be found in his entry in the D.N.B. He seems to have become involved out of friendship and perhaps appreciation of the opportunity offered to establish a first rate hospital for children. For, since the economy of funds was not a priority, the Evelina was designed and built as a model institution, whereas other paediatric hospitals had originally to make the best of converted old buildings. Also the Evelina was unusually large, intended for about 100 inpatients, although only thirty cots were used initially. The idea was to increase intake as subscriptions and donations flowed in, but here the Baron would be disappointed by the relative paucity of local support. As will be seen, he was more or less left to fund the institution himself because it was perceived as his personal domain. Indeed the hospital was run by the Baron and his friends as a private charity until the early 1890 s when more open management was instituted.

People were relatively easily persuaded in the sixties to support paediatric institutions, in part because the earlier enterprises were seen to be successful. Annual reports emphasized the steady increase in demand for outpatient services and the need for more

\footnotetext{
57 Rachel Waterhouse, Children in Hospital: A Hundred Years of Child Care in Birmingham (London: Hutchinson, 1962), pp. 23-5.

58 'Obituary: Thomas Pretious Heslop, M.D., F.R.C.P.', Lancet, i (1885): 1185-6.

59 A brief history of the hospital is provided by H. E. Priestley, The Evelina: The Story of a London Children's Hospital, 1869-1969 (London: Guy's Hospital, 1969).
} 
beds, and for more money, while usually omitting any discussion of contentious subjects such as the incidence of infectious diseases on the wards. If anyone had truly believed the hospitals would be under used, this fear was laid to rest. Perhaps more importantly, the early nineteenth-century concept of family life as such an ideal setting for child rearing that its privacy and intactness must be protected from outside scrutiny, or from potentially interfering institutions, was again seriously undermined by revelations of parental indifference, or even active cruelty, to the point of causing or hastening the demise of their offspring. In the late 1850 s the press began drawing attention to the crime of infanticide, deemed to be on the rise, and also to the practice of quietening infants with opiates that could, by accident or by design, lead to sudden death. ${ }^{60}$ By the 1860 s this alleged 'slaughter of the innocents' was the pressing concern of a wide group of reformers who formed an Association for the Preservation of Infant Life. ${ }^{61}$ Their concern does not seem to have been misplaced for, according to Behlmer, infants then formed a much higher proportion of murder victims than is true today. 'From the 5,314 cases of homicide listed by the Registrar General for the period 1863-87, a grim 3,355 cases-or 63 percentinvolved infants. By contrast', Behlmer continues, 'in 1977 only 6.1 percent of all English murder victims were children under one year of age'. ${ }^{62}$ The mid-Victorian public was outraged to read of infants killed by baby farmers, sometimes with the connivance of the mother. Another institution suspected of being associated with infanticide was the practice, apparently common in Lancashire, of insuring the child's life at birth. Belonging to a 'burial club', reformers believed, was tantamount to encouraging neglect, if not infanticide. According to John Brendon Curgenven, secretary of the Harveian Society, who in 1866 persuaded its members to investigate child murder, 'it would appear that from the moment the death of a child is systematically contemplated and provided for, it is likely to be neglected or less anxiously watched, and its chances of life diminished' ${ }^{63}$ There was inconsistency in this condemnation of working people for ensuring the wherewithal to afford a decent burial while praise was offered for foresight in joining provident societies for the maintenance of health. As Walton indicates, the burial clubs 'prevented the ultimate stigma of a pauper funeral', but this reason for their popularity among Lancashire working-class families was ill-understood by middle-class commentators who were more likely to judge such action as the misplaced use of scarce funds, if not a premeditated move to capitalize on death. ${ }^{64}$

${ }^{60}$ For histories of cruelty to children see: George K. Behlmer, Child Abuse and Moral Reform in England, 1870-1908 (Stanford: University Press, 1982); F. B. Smith, The People's Health 1830 to 1910 (London: Croom Helm, 1979), pp. 78-81; Anthony S. Wohl, Endangered Lives: Public Health in Victorian Britain (London: J. M. Dent, 1983), pp. 33-7. On the topic of opiates administered to infants see: Virginia Berridge and Griffith Edwards, Opium and the People: Opiate Use in Nineteenth-Century England (London: Allen Lane, 1981), pp. 97-105; Margaret Hewitt, Wives and Mothers in Victorian Industry (London: Rockliff, 1948), pp. 141-52; Elizabeth Lomax, 'The Uses and Abuses of Opiates in Nineteenth-Century England', Bulletin of the History of Medicine, 47 (1973): 167-76.

${ }^{61}$ Contemporary reports include: 'Infanticide', The Times, 2 August (1865): 9; J. B. Curgenven, The Waste of Infant Life (London: Faithful and Head, 1867); 'Baby-farming and Child-murder', British Medical Journal, i (1868): 75; E. Ballard, 'Baby Killing', British and Foreign Medico-Chirurgical Review, 45 (1870): 346-70.

62 Behlmer, Child Abuse, p. 18.

63 Curgenven, The Waste of Infant Life, pp. 13-14.

64 Walton, Lancashire, p. 181. 


\section{The Origins of British Paediatric Hospitals}

Less dramatic than the concept of infanticide, but reinforcing the perception of working-class parents as irresponsible, was the conviction that the high infant mortality prevalent in many industrial districts was mainly due to mothers being out working. A cause and effect relationship seems originally to have been suggested by John Simon, a surgeon who was appointed Medical Officer to the General Board of Health in 1855, and then, on dissolution of this Board in 1858, Medical Officer to the Privy Council. At the time the Registrar-General's reports provided information as to general death rates without suggesting causes for differences in mortality between various districts. ${ }^{65} \mathrm{Simon}$, and Edward H. Geenhow, lecturer in public health at St. Thomas's Hospital, found that by using unpublished data from the Registrar-General's Office they could establish the number of persons that had died of specific diseases, or groups of diseases, in all areas between 1848 and $1854 .{ }^{66}$ For twenty selected districts, Greenhow also established the ages during which specific illnesses were most fatal. In an introduction to this report, Simon indicated that scarlet fever, measles, whooping cough and smallpox killed about 37,000 persons annually, of whom three-quarters were under the age of five years. The first three of these diseases were nearly three times as fatal to children in the industrial north-west as to children in the south-east, probably due to overcrowding and defective ventilation which would facilitate cross infection. But when it came to acute noninfectious diseases, such as convulsions, diarrhoea and respiratory disorders, which together destroyed about 72,000 children a year, the death rate in large manufacturing towns was seven times greater than in the three healthiest districts of England due, according to Simon, to defective home sanitation and to the neglect of infants by their working mothers.

As a check on these findings, Simon later sent Greenhow to investigate certain Midland and Welsh towns returning high infant mortality rates, and also dispatched Dr. Julian Hunter to make inquiries in rural districts where, inexplicably, babies were dying in unusually large numbers. ${ }^{67}$ Similar accounts ensued of mothers working and leaving their babies to the indifferent care of old women or young girls, to be hand fed and sometimes drugged with opiates for the sake of peace and quiet. In the agricultural area visited by Hunter, women laboured in the fields as members of mixed gangs, so being easy victims of seduction and often burdened with unwanted children. To mitigate such evils Simon proposed legislation to control the sale of dangerous drugs and nurseries for infants in factories with substantial numbers of female employees.

As Royston Lambert has indicated, Simon realized that these would be only superficial remedies since 'the root of the evil is an influence with which English law has never professed to deal. Money is on one side; penury on the other . . . the poor factory-woman, who meant only to sell that honest industry of hers, gradually finds that she has sold

\footnotetext{
65 Royston Lambert, Sir John Simon, 1816-1904, and English Social Administration (London: MacGibbon \& Kee, 1963), p. 262.

${ }^{66}$ Papers Relating to the Sanitary State of the People of England by E. H. Greenhow, with Introduction by John Simon, B.P.P., 1857-8, XXIII, pp. 267-478.

${ }^{67}$ Dr. Greenhow's Report on the Circumstances under which there is an Excessive Mortality of Young Children among Certain Manufacturing Populations, B.P.P., 1862, XXII, pp. 651-60; Report by Dr. Henry Julian Hunter on the Excessive Mortality of Infants in some Rural Districts of England, B.P.P., 1864, XXVIII, pp. 454-62.
} 
almost everything which other women understand as happiness' ${ }^{68}$ But as the problem of high infant mortality and its fairly constant correlation with maternal employment became publicized in the sixties, many reformers simply reacted in horror at the fecklessness displayed by absentee mothers. ${ }^{69}$ What critics usually failed to take into account was the near impossibility of getting a steady income through labour at home, as had been feasible with trades such as weaving and lace making earlier in the century, and the possibility that families, including babies, might be even worse off without the mothers' wages. Modern research indeed suggests that absence of this extra money was often related to lower standards of nutrition, and that anyway most mothers with young children did not go out to work in factories. ${ }^{70}$ The overwhelming majority of operatives seem to have been young, unmarried girls. But the image of hordes of absentee mothers prevailed, and because maternal employment was regarded as a sign of parental irresponsibility rather than necessary for family survival, little serious thought was given to enabling women to work whilst their children were properly cared for. Since this is once again an unresolved problem in Britain and particularly in the United States, even though nowadays maternal employment generally receives approval, we cannot be too censorious of our Victorian forebears who were facing the dilemma for the first time, and were even more fearful of state intervention. Furthermore, crèches were tried out, to a limited extent. As will be seen, in the early 1860s Charles West instituted an infant nursery for working mothers at Great Ormond Street but, in spite of its apparent popularity with parents, this was phased out about ten years later when both the space and the funds required were appropriated for more conventional hospital functions. Cruickshank also points out that by 1870 three day nurseries had been established in Manchester and Salford with more to come, launched by volunteers or employers, but that on the whole these institutions were regarded with suspicion by mothers who preferred child minders known to them. ${ }^{71}$ More radical measures, such as insurance schemes, initiated in France, to which employers and female workers contributed to enable mothers to take time off with pay after childbirth, were considered in England but not implemented. ${ }^{72}$

The national exposure of instances of parental cruelty to children and, less dramatically, awareness that labouring-class mothers might not be at home minding their babies, forced a reappraisal of the facile concept of generalized domestic bliss, reducing its effect as a reason, or an excuse, for not donating to institutions intended for the welfare of the young. Although the more prosperous Victorians were still tolerating such abuses as long hours of child labour, the incarceration of illegitimate and unwanted children in workhouses, and work obviously dangerous to the young such as chimney sweeping, they reacted with

\footnotetext{
68 Lambert, Sir John Simon, pp. 336-7.

69 Infant mortality and the employment of mothers formed a subject frequently discussed by members of the National Association for the Promotion of Social Science, formed in 1856. A bibliography of relevant papers published in the Transactions of the National Association for the Promotion of Social Science may be found in: Hewitt, Wives and Mothers in Victorian Industry, pp. 229-31.

${ }^{70}$ Berridge and Edwards, Opium and the People, p. 101; and Barbara Thompson, 'Infant Mortality in Nineteenth-Century Bradford,, in Robert Woods and John Woodward (eds), Urban Disease and Mortality in Nineteenth-Century England (London: Batsford, 1984), pp. 120-47.

71 Cruickshank, Childen and Industry, p. 106.

72 Thomas M. Dolan, 'How does the Employment of Mothers in Mills and Manufactures Influence Infant Mortality; and Ought any, and, if so, what, Restrictions to be Placed on such Employment?' Transactions of the National Association for the Promotion of Social Science (1882): 357-66.
} 


\section{The Origins of British Paediatric Hospitals}

horror to evil situations sufficiently well publicized. What was needed, as so well perceived by Charles Dickens, was an appeal to sentiment and a depiction of the child as innocent victim. What gradually emerged was a conviction that poor children, sometimes even babies, might actually be better off in institutions designed for their care than left at home with their families. By the end of the century acute paediatric hospitals had been supplemented by convalescent homes, hospitals for long-stay crippled children and holiday homes for delicate slum children, all intended to enhance child health in a more ideal environment than home could provide.

In their annual reports committees of management fluctuated between depicting the parents of patients as decent, hardworking but poor persons who could not afford the fees charged by medical practitioners and so had nowhere else to turn, or as vicious or neglectful people. Sometimes both possibilities were included in the same report. In 1861 the governors of the General Hospital and Dispensary for Children, Manchester, once again reminded their subscribers of the 'shocking preeminence which Manchester and Salford occupy among the large European cities in the proportion of infant mortality'. They went on to state that 'the bulk of those who attend in our outpatient rooms belong to the most destitute class, who have no other means of obtaining competent medical advice'. The governors praised the work of the institution,

... in counteracting the thousand named and nameless evils which attend bad feeding and bad nursing, or the neglect and vices of parents; and which either nip in the bud the precious lives of these "little ones," or cause them to grow up sickly and diseased men and women, - their lives too often a burden both to themselves and other! ${ }^{73}$

Charity, it would seem, was no longer quite so destructive to the receiver. The wealthy should donate, according to the hospital governors, out of Christianity, out of humanity, out of political economy: 'for the loss of so large a proportion of the population is a drawback on the prosperity of the people', out of expediency: 'for the poor cannot suffer in a large community, without injuriously affecting every other class', and out of shame: 'for certainly a stigma rests upon the town that does not exert itself to mitigate an acknowledged evil'. ${ }^{74}$

Such exhortations would continue for the rest of the century, being more successful in some districts than in others. In Glasgow, for example, it would take more than twenty years of arguments and pleas before sufficient local support for a paediatric hospital could be obtained. As indicated by Edna Robertson, a group of physicians, clergymen, and other influential citizens had resolved to establish a children's hospital as early as 1861 but would not be successful until 1882. ${ }^{75}$ Opposition came in part from the directors of the Glasgow Royal Infirmary (where about 170 children were treated in 1861) who feared that a children's hospital would siphon off funds from their own institution. When the Hospital for Sick Children was finally established Glaswegians supported it in moderation. In 1899 , according to Burdett, the hospital had a total income of $£ 3,495$ (plus legacies

\footnotetext{
73 Thirty-third Annual Report of the General Hospital and Dispensary (Manchester, 1862), p. 6.

74 Ibid., p. 7.

75 Edna Robertson, The Yorkhill Story: The History of the Royal Hospital for Sick Children, Glasgow (Glasgow: University Press for Yorkhhill and Associate Hospitals Board of Management, 1972), pp. 17-27, for a description of the difficulties that beset the founders.
} 
amounting to $£ 2,591$ and donations of $£ 1,100$ ) while the Manchester Children's Hospital (Pendlebury and Gartside Street) was at least twice as well off with a total income of $£ 7,315$ (plus legacies of $£ 12,190$ and donations of $£ 1,100$ ). ${ }^{76}$ As a consequence the latter hospital had twice as many cots (140 versus 74$)$ to serve approximately the same population. (Manchester was smaller than Glasgow, but not when the adjoining city of Salford was included. According to the Registrar-General's Report for 1890, Manchester then had a population of 379,437 , Salford a population of 242,509 , and Glasgow a population of 530,208$).{ }^{77}$ However, comparisons as to city size may not be very relevant since the provincial hospitals usually also served large outlying areas, unlike the London hospitals which tended to take patients mainly from their own locality. As with the general hospitals, London supported a larger concentration of paediatric hospitals for its population than did the provincial cities, probably in the main because of its attraction to physicians as the capital city. Reformers would complain that far more money per head of population was spent in London on voluntary hospitals and dispensaries than in the other English cities. The hospitals were clustered in the centre of the metropolis and comparatively scarce in the ever expanding outlying areas. According to evidence given to the Select Committee of the House of Lords on Metropolitan Hospitals in the early nineties, nearly all the voluntary hospitals lay within an area of about two square miles north and west of the river. ${ }^{78}$ The paediatric hospitals were better distributed than most, with the North Eastern and the East London sited in the east end, and the Evelina south of the Thames, if only just.

By the end of the century about twenty-four acute paediatric hospitals had been founded in Great Britain and the largest of these also possessed convalescent homes in the country where selected patients could further recuperate from illness or surgery. In addition children's cots were to be found in various hospitals for women and children, and some provision had been made in special homes for the care of chronically sick children who were not usually admitted to the general paediatric hospitals for fear of blocking beds. In the meantime general hospitals, both large and small, were giving up the idea of casually admitting young patients to adult wards, and instituting instead their own children's wards. In Lancashire, Oldham Infirmary opened a ward for children in 1878, Bolton Infirmary was rebuilt in 1883 with a 'wing' for young patients, and the infirmaries at Preston and Blackburn instituted paediatric wards in the $1880 \mathrm{~s} .{ }^{79}$ The general hospital at Altrincham, a small Cheshire town about nine miles from Manchester, was opened in 1870 (having been founded as a dispensary for poor children in 1858, and changed into a provident dispensary in 1861). In 1890 Altrincham General Hospital was expanded to hold forty-four beds, including a ward for children. ${ }^{80}$

\footnotetext{
76 Henry Burdett, Hospitals and Charities 1901 (London: Scientific Press, 1901), p. 428 (Manchester), and p. 547 (Glasgow).

77 'Miscellanea-Registrar General's Report for the Year Ending 1890, D.-Special Town Table', Journal of the Royal Statistical Society, 54 (1891): 192.

${ }_{78}$ Select Committee of the House of Lords on Metropolitan Hospitals, Third Report, B.P.P., 1892, XIII, para. 227-230.

${ }^{79}$ Cruickshank, Childen and Industry, pp. 126-7.

80 Charles Nickson, Bygone Altrincham: Traditions and History (Didsbury, Manchester: E. J. Morten, 1935), pp. 234-6.
} 


\section{The Origins of British Paediatric Hospitals}

Had children's departments been instituted in the general hospitals at mid-century, there would have been little need for the special hospitals. However, this did not happen partially because of lack of interest in diseases of children but also for fear of increasing infection, which was then the bugbear of all hospitals. Children were known to be liable to all kinds of eruptive fevers whose degree and method of infectivity were ill understood at mid-century. Florence Nightingale proposed that the best method of mitigating infection was to scatter sick children among adult patients, so diluting the miasma emanating from the fevered small patient. 'But, whatever you do', she wrote, 'do not have children's wards in a general hospital. There at least mix up the children with the adults. For a children's ward in a general hospital combines all the disadvantages with none of the advantages of a children's hospital' ${ }^{81}$ In most general hospitals her advice was heeded until nearly the end of the century, by which time it was understood that infectious diseases were due to a specific germ and not to a general miasma, or air polluted by decomposed organic material, as Miss Nightingale had firmly believed. But had beliefs been otherwise, and the teaching hospitals developed paediatric wards sooner, medical students would perforce have learned something about the diseases of children. This they hardly did until the twentieth century, since it was time consuming, and unnecessary, for them to attend the small and scattered paediatric hospitals. From the children's viewpoint, however, having their own hospitals was advantageous. For here the whole institution was dedicated to their care and nursing was especially fine tuned to their needs. Also there were other benefits, such as greater ease in providing diets and medicines suitable for children and in ensuring an adequate and safe supply of milk. In large general hospitals such matters might have commanded little attention.

81 Florence Nightingale, Notes on Hospitals (London: Longmans, Green, 1863), pp. 125-6. 